\title{
THE FIBRINOLYTIC ENZYME SYSTEM IN NORMAL, HEMORRHAGIC AND DISEASE STATES ${ }^{1}$
}

\author{
By LOUISE LANG PHILLIPS AND VALIJA SKRODELIS
}

\author{
(From the Department of Obstetrics and Gynecology, College of Physicians and Surgeons, \\ Columbia University, New York, N. Y.)
}

(Submitted for publication February 6, 1958; accepted March 14, 1958)

The recognition that hypofibrinogenemia may be an important factor in the hemorrhagic diathesis which occurs in a number of pathological states has given rise to an increased study of this phenomenon. In many of these conditions an accompanying fibrinolysin has been reported. However, evidence as to the presence of this enzyme varies from investigator to investigator and from method to method.

Therefore, a study has been undertaken to investigate as quantitatively as possible the various factors of the fibrinolytic enzyme system. Early in the investigation it became evident that an active fibrinolysin could be detected only transiently in the blood and that a large part of the discrepancy found in the literature may have been a result of the particular time at which the sample was drawn. It has been frequently observed that lysis of plasma clots at all dilutions may occur at one stage, and yet a blood sample drawn an hour later, which has a lower fibrinogen level, may show no evidence of lysis. Indirect evidence obtained from a changing profibrinolysin or inhibitor level may, therefore, give more information as to what is occurring intravascularly than does the presence or absence of an active fibrinolysis.

The following set of experimental tests has been set up as a routine for examining blood from patients with hemorrhagic tendencies which are suspected to be in the field of hypofibrinogenemia or fibrinolysin. These tests have also been applied to a number of normal subjects, pregnant women, obstetrical patients with abruptio placentae, patients undergoing portacaval shunt for cirrhosis of the liver, as well as patients with carcinoma and other disease states.

1 This investigation was supported by Research Grant H-1512 from the National Heart Institute, National Institutes of Health, United States Public Health Service.

\section{METHODS}

Fibrinogen determinations are made by the method of Ratnoff and Menzie (1).

Plasma profibrinolysin, active and "free" (streptokinase-activatable, in the presence of plasma inhibitors). This is a method similar to that of Scott, Matthews, Butterworth, and Frommeyer (2) but the details have been worked out independently in this laboratory and have been reported previously (3). However, since earlier reports, it has been found necessary to change to a casein substrate since the commercial fibrinogen is no longer suitable for these studies (presumably because of the presence of large quantities of profibrinolysin). Although this determination now represents the hydrolysis of casein rather than the more specific fibrinogen molecule, the original term has been retained.

Into each of three conical centrifuge tubes containing $0.9,0.9$, and $0.85 \mathrm{ml}$., respectively, of $0.05 \mathrm{M}$ phosphate

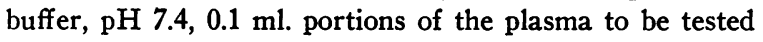
are pipetted. To Tube 3 is added $0.05 \mathrm{ml}$. of streptokinase ${ }^{2}$ $(10,000 \mu$ per $\mathrm{ml}$.). One $\mathrm{ml}$. of 1 per cent casein solution is then added and the proteins of Tube 1 are immediately precipitated with $3 \mathrm{ml}$. of 5 per cent trichloracetic acid. The other tubes are then incubated in a water bath at $37^{\circ} \mathrm{C}$. for two hours before hydrolysis is stopped and the proteins are precipitated with trichloracetic acid. After standing one hour, the tubes are centrifuged and the optical density of the supernatant solution is measured in a Beckman spectrophotometer using as a blank a solution prepared by mixing casein, buffer and trichloracetic acid in the proportions given above.

The difference in optical density between the supernatant of Tubes 1 and 2 is a measure of the active proteolytic enzyme found in the plasma. Only in rare instances is significant activity demonstrable. The difference in optical density between Tubes 1 and 3 is an indication of the active plus the profibrinolysin which can be activated by means of streptokinase. The actual units of fibrinolytic activity can then be read from a previously prepared calibration curve relating optical density to units of activity (4). The units of active enzyme should be subtracted from those obtained after addition of streptokinase in order to determine the profibrinolysin. However, since inhibitors of the enzyme are present in

2 Varidase ${ }^{\circledR}$ from Lederle Laboratories Division, American Cyanamid Company. 
the plasma, not all of the activated enzyme is available for hydrolysis. The plasma profibrinolysin then represents only that which is not inhibited and will be called hereafter "free" profibrinolysin.

Total active and profibrinolysin. In order to obtain the uninhibited enzyme, the inhibitors are removed by precipitating the fibrinolytic enzyme at $\mathrm{pH} 5.1$ and low ionic strength as first described by Milstone (5). Plasma $(0.5 \mathrm{ml}$.) is diluted 1 to 20 with distilled water, and 0.15 $\mathrm{ml}$. of 1 per cent acetic acid is added. The solution is allowed to stand overnight in the refrigerator and then centrifuged. The supernatant containing the inhibitors is discarded and the precipitate is dissolved in $0.5 \mathrm{ml}$. of phosphate buffer. This solution is then tested in the same manner as was the plasma for active and streptokinase-activatable profibrinolysin. Any active enzyme found in this euglobulin precipitate must be subtracted from that found after activating with streptokinase to obtain the total profibrinolysin. This calculation should be made after optical density has been converted into units of fibrinolysin by means of the calibration curve since there is not a straight line relationship between optical density and fibrinolytic units.
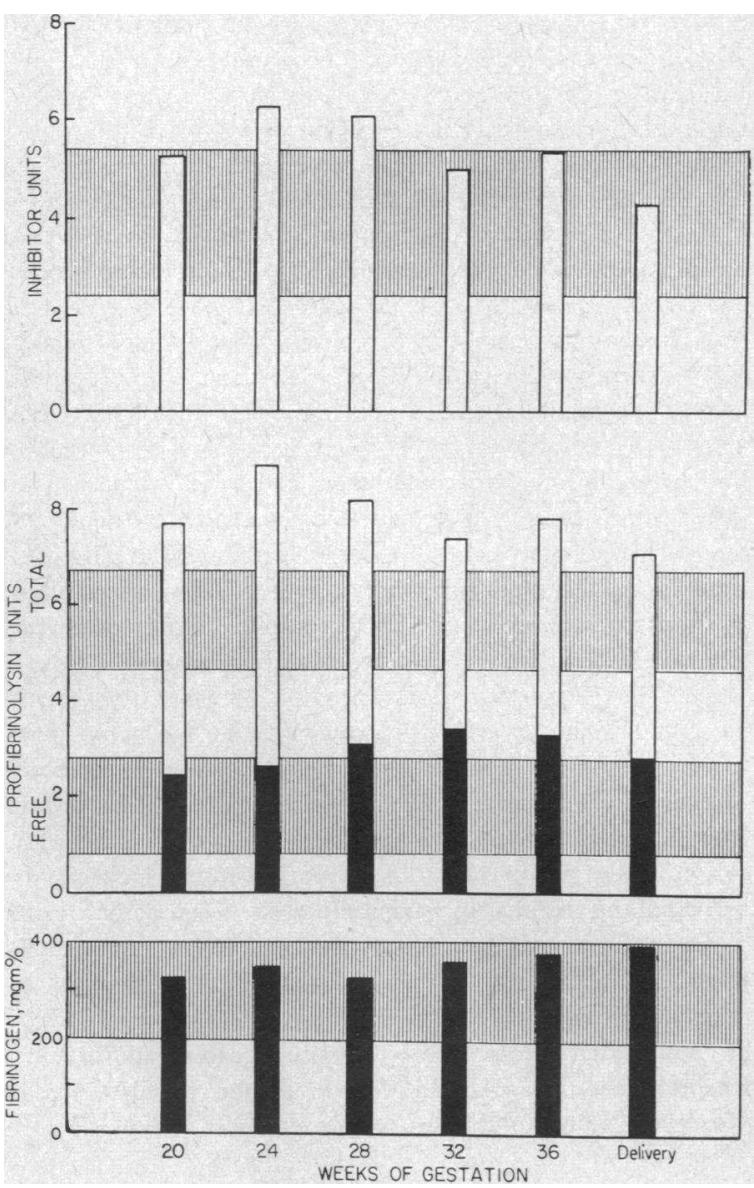

Fig. 1. Fibrinolytic Enzyme Activity in Normal PREgNANCY
In the cases reported here no active enzyme was found in either the plasma or euglobulin precipitate. However, since it does occur in some cases, the method and precautions concerning the calculations of profibrinolysin have been discussed in this paper.

Inhibitors. The difference between the total profibrinolysin found in the iso-electric precipitate and the free proenzyme found in the plasma is a measure of the inhibitors contained in the plasma. On rare occasions when a severe afibrinogenemia is encountered, the profibrinolysin of the iso-electric precipitate may be equal to or even less than that found in plasma. This suggests that the enzyme may not be precipitated 100 per cent but there is probably close to 90 per cent precipitation.

Modified Coon's test (6). Plasma is diluted serially with saline to a dilution of 1 to 64 . The plasma is then clotted by the addition of thrombin ${ }^{3}$ (10 units) and the clots allowed to stand at room temperature for 24 hours. The lysis is scored from minus to 6 plus, depending upon the number of tubes showing complete disappearance of the clot in 24 hours. If lysis is observed in less than 24 hours the time is recorded. Only complete disintegration of the clot (as opposed to 50 per cent lysis, as used by Coon) is reported since clot retraction makes this 50 per cent difficult to estimate.

Optical density. In addition to the above determinations, a measure of the optical densities of the trichloracetic acid (TCA) soluble products in the plasma, as determined in the Beckman spectrophotometer at 260, 280, and $295 \mathrm{~m} \mu$, is made. It was originally felt in this laboratory that an increase in the products indicated intravascular hydrolysis of fibrinogen. While it is still believed that a transient increase in optical density at these wave lengths may be an indication of fibrinolysis, it has become evident that these substances are also increased in a number of disease states. During pregnancy there is a slight rise which is more evident in cases of toxemia of pregnancy. In cases of advanced carcinoma these substances may be markedly increased. Acute infection, particularly where accompanied by urinary retention, may increase the levels five- to tenfold. These TCA soluble substances may be mucoproteins and/or breakdown products of nucleic acids and proteins which may occur under conditions in which increased catabolism presumably might be expected. It is recognized that optical densities, while giving straight line relationships with amino acids, need to be used with caution when carried over to fibrinolytic plasma digests or to plasma altered in vivo.

With the exception of the fibrinogen determination and sometimes the Coon's test these methods are too time consuming to be useful for emergency diagnosis. However, the fibrinogen level, which can be estimated qualitatively in 10 minutes or completed quantitatively in $\mathbf{4 5}$ minutes, is the most important determination in following the patient's condition. The other determinations, as outlined, can then be made in an effort to elucidate the processes involved in production of an acute afibrinogene-

${ }^{3}$ Parke Davis bovine thrombin. 


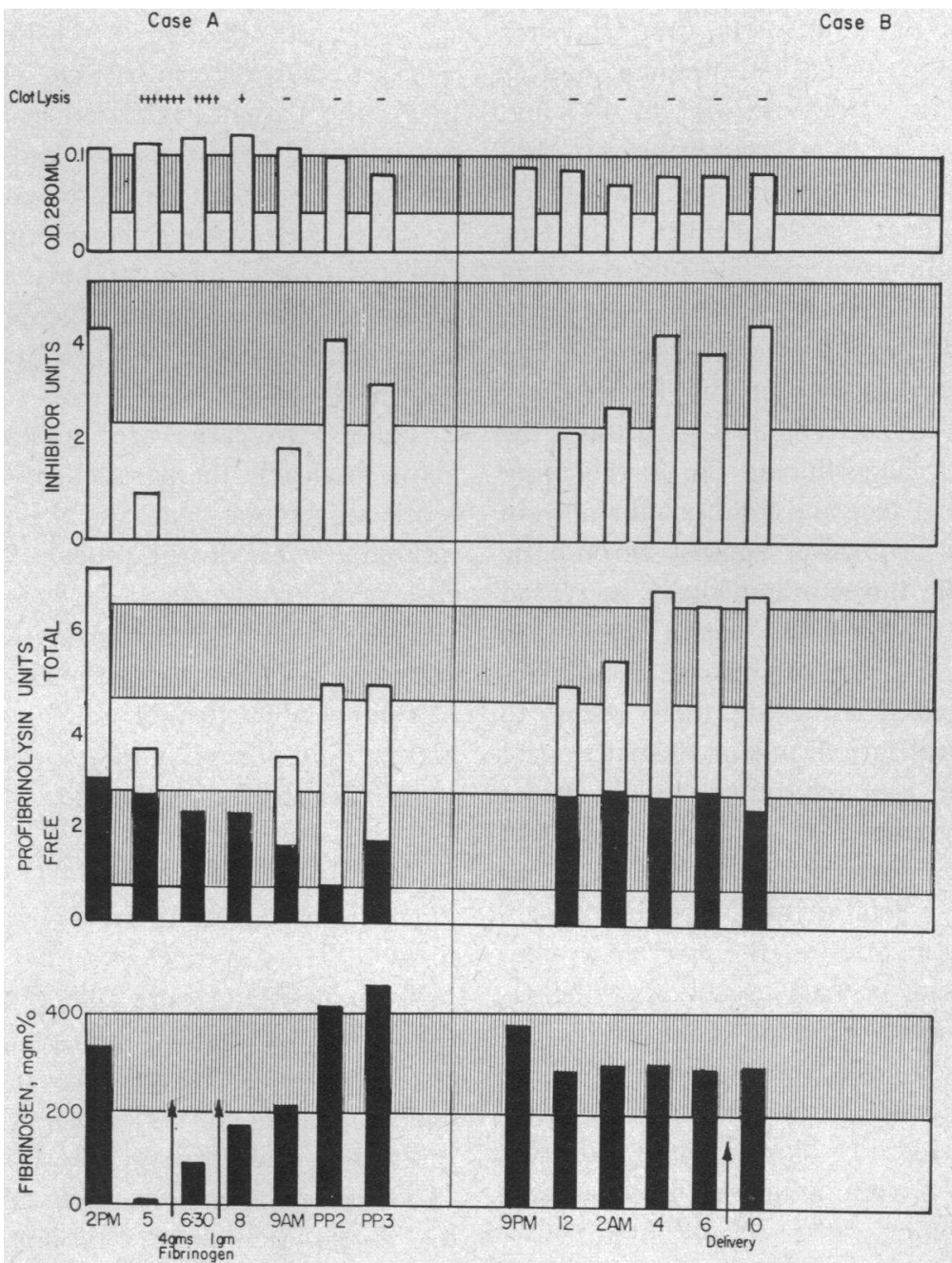

Fig. 2. Fibrinolytic Enzyme Activity in Abruptio Placentae

mia after the immediate crisis has passed, or to study more chronic conditions.

\section{RESULTS}

The cross hatching in the following figures represents the ranges to be expected for normal nonpregnant subjects. Two hundred to $400 \mathrm{mg}$. per cent of fibrinogen [that obtained by Ratnoff and Menzie (1)] has been used as the normal range for this substance. The ranges for other factors represent those expected in 99 per cent of the population as determined from the mean plus or minus 2.5 times the standard deviation for each factor. The results of the statistical analyses are as follows. Free profibrinolysin: Mean, 1.8; S.D., 0.4 ; range, 0.8 to 2.8 . Total profibrinolysin:
Mean, 5.7 ; S.D., 0.4 ; range, 4.7 to 6.7. Inhibitors : Mean, 3.9, S.D., 0.6; range, 2.4 to 5.4. Optical density at $280 \mathrm{~m} \mu$ : Mean, 69; S.D., 12; range, 39 to 99 .

\section{Pregnancy}

Since it is in obstetrical practice that most cases of afibrinogenemia are found, the factors of the fibrinolytic enzyme system were studied throughout pregnancy in a group of approximately 50 women with normal antepartum, delivery, and postpartum courses. In Figure 1 are charted the averages of figures obtained for these patients at approximately the period of pregnancy indicated. Not all patients are represented at each level.

The fibrinogen level rises gradually from an 
average of $300 \mathrm{mg}$. per cent in the first trimester [this agrees well with normal nonpregnant figures reported by other investigators (1)] to $400 \mathrm{mg}$. per cent at term. The total profibrinolysin and inhibitor levels rise to a maximum in the second trimester and then decrease somewhat. The free profibrinolysin continues to increase into the third trimester.

The increase in fibrinogen and other clotting factors (7) has been interpreted by Fresh, Ferguson, and Lewis as a mechanism to protect the mother from hemorrhage during the forthcoming delivery. The higher free and total profibrinolysin may in turn be a protection against thrombotic complications, while the simultaneously increased inhibitors appear to hold the entire system in check. However, in spite of the rise in all factors during the second trimester, there seems to be a considerable utilization and/or destruction of both profibrinolysin and inhibitors at delivery of even a normal pregnancy. It is conceivable, then, in the case of an obstetrical accident such as abruptio placentae or fetal demise, that the process of activation and utilization of the enzyme system may be accelerated to such an extent that the intravascular fibrinogen may be completely destroyed. In such a case significant fibrinolytic activity may or may not be demonstrable depending on the time at which the blood sample is drawn.

Figure 2 shows a comparison of two patients with abruptio placentae. Case A, although showing normal levels of all factors at the time Cesarean section was performed to save the infant, developed an afibrinogenemia and severe hemorrhage approximately three hours post delivery. Five grams of fibrinogen plus whole blood replacement restored the clotting mechanism, and vital signs were stabilized within two hours after hemorrhage started. All factors of the fibrinolytic enzyme system (fibrinogen, "free" and total profibrinolysin, and inhibitors) fell precipitately during the period before hemorrhage occurred, but rose again gradually as the patient recovered.

In Case B, the fetal heart was not heard at the time of admission to the hospital and conservative treatment was therefore decided upon in spite of considerable bleeding. However, fibrinogen levels were followed carefully during the course of labor. Although there was an initial drop in fibrinogen and perhaps in other factors (the quan- tity of blood obtained in the first sample was insufficient for determinations other than fibrinogen), the patient stabilized at levels well within normal range of fibrinogen and total profibrinoly. sin, and the inhibitors increased from low normal levels to well within the average range. A low forceps delivery of a stillborn infant was accomplished without undue incident approximately eight hours after the original diagnosis of abruptio placentae was made.

These two cases are presented because they show so clearly the parallelism between fibrinogen levels on the one hand and the profibrinolysin and inhibitor levels on the other. Whenever a severe case of afibrinogenemia is encountered in obstetrics, the levels of profibrinolysin and inhibitors are also low. However, even in cases of abruptio placentae when profibrinolysin and inhibitors remain within normal limits, the fibrinogen usually is also found to be adequate for normal clotting.

\section{Cirrhosis of liver}

In Figure 3 results are presented of determinations on blood samples from two patients on whom portacaval shunts were performed for cirrhosis of the liver. In Case $\mathrm{C}$, the first sample was drawn at completion of the anastomosis when generalized oozing from all cut surfaces was becoming an acute problem. The fibrinogen level was somewhat low (168 mg. per cent) as were the other factors of the fibrinolytic system, although these were typical of the levels found in cirrhotic patients. A 6 plus lysis of plasma clots occurred within one hour. The patient was losing nearly one liter of blood every 15 minutes. This was being replaced with whole blood. In spite of 8 grams of fibrinogen, the level continued to fall ( $46 \mathrm{mg}$. per cent) and the patient was returned to the operating room for re-exploration. A small puncture in the vena cava was found and repaired and more blood and fibrinogen were administered. Although the fibrinogen level rose somewhat, total profibrinolysin and inhibitors continued to decrease and the patient expired approximately six hours after the completion of the original operation.

Case D shows results obtained before and during the operation on another cirrhotic patient. On admission one week before the operation, this patient's levels (except for fibrinogen) were essentially the same as those found in the initial de- 


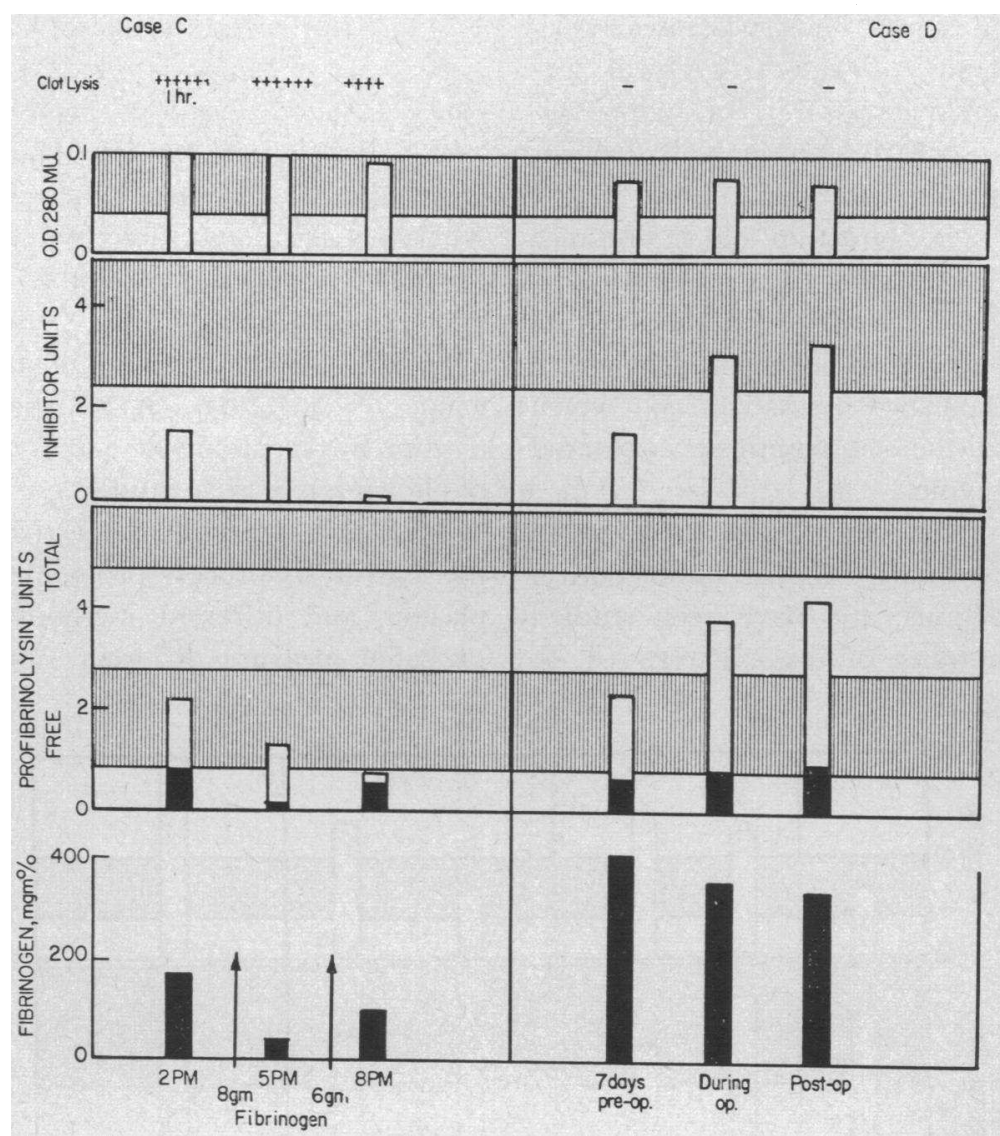

Fig. 3. Fibrinolytic Enzyme Activity in CirRhosis of Liver

termination of Case C. However, after preoperative administration of albumin, the total profibrinolysin and inhibitors had risen to nearly normal and a portacaval shunt was performed on this patient without difficulty.

\section{Other pathological processes}

In Figure 4, the results obtained with normal subjects are contrasted with three groups of pathological patients: $A$ ) Averages obtained from patients with benign prostatic hypertrophy and with carcinoma of the prostate; $B$ ) Typical cases of early and advanced carcinoma of the cervix; and C) A case of severe septic abortion.

No cases of hypofibrinogenemia were encountered in this series of cases with prostatic carcinoma. In fact, averages for fibrinogen figures were found to be higher than those of normal controls and of those with benign prostatic hypertrophy. Other factors of the fibrinolytic system were within normal limits, except for the free profibrinolysin which showed somewhat high averages. However, optical densities of most patients with prostatic carcinoma were found to be considerably elevated. Similar results were obtained with advanced cervical cancer except that frequently an exceedingly high fibrinogen level was encountered. Early cancer of the cervix showed perfectly normal levels for all factors.

Although fibrinogen levels may vary widely in cases of severe infection, they tend to be somewhat high as shown in Figure 4. The "free" profibrinolysin is frequently exceedingly low with the total profibrinolysin in a low normal or slightly below normal range. The inhibitors usually remain within normal limits. High optical densities may also be encountered when infection is overwhelming.

\section{DISCUSSION}

The fibrinolytic enzyme system is a complicated system consisting of proenzyme(s), activators, ac- 
tive enzyme(s), inhibitors and substrates. Because of the complexity of factors involved, it is difficult to determine whether one or more substances are involved in each step of the hydrolysis process. However, the confusion found in the literature as to the mode of action and importance of this enzyme in afibrinogenemia suggests that many investigators are studying different aspects of the enzyme system. An excellent review article has recently been published by Astrup (8) which describes in detail all the complexities encountered in a study of the enzyme.

Tissue activators have been found to exist in almost all tissues, primarily in the mitochondria and microsome fractions, and have been studied extensively by a number of investigators $(4,9$,
10). It has been demonstrated that activation by tissue extracts may produce fibrinogenolytic activity but not fibrinolytic activity, or vice versa (4). This is substantiated by the fact that occasionally plasma clots will be lysed in samples where no caseinolytic activity can be demonstrated, or that caseinolytic activity is encountered when no clot lysis occurs.

Tissue activation is the most probable pathway encountered in vivo, but the speed and ease of activation by streptokinase makes it the usual method of choice for in vitro studies.

Inhibitors to both the activation process and the hydrolysis process probably are present in the plasma, and different methods of determination probably measure different substances. One set

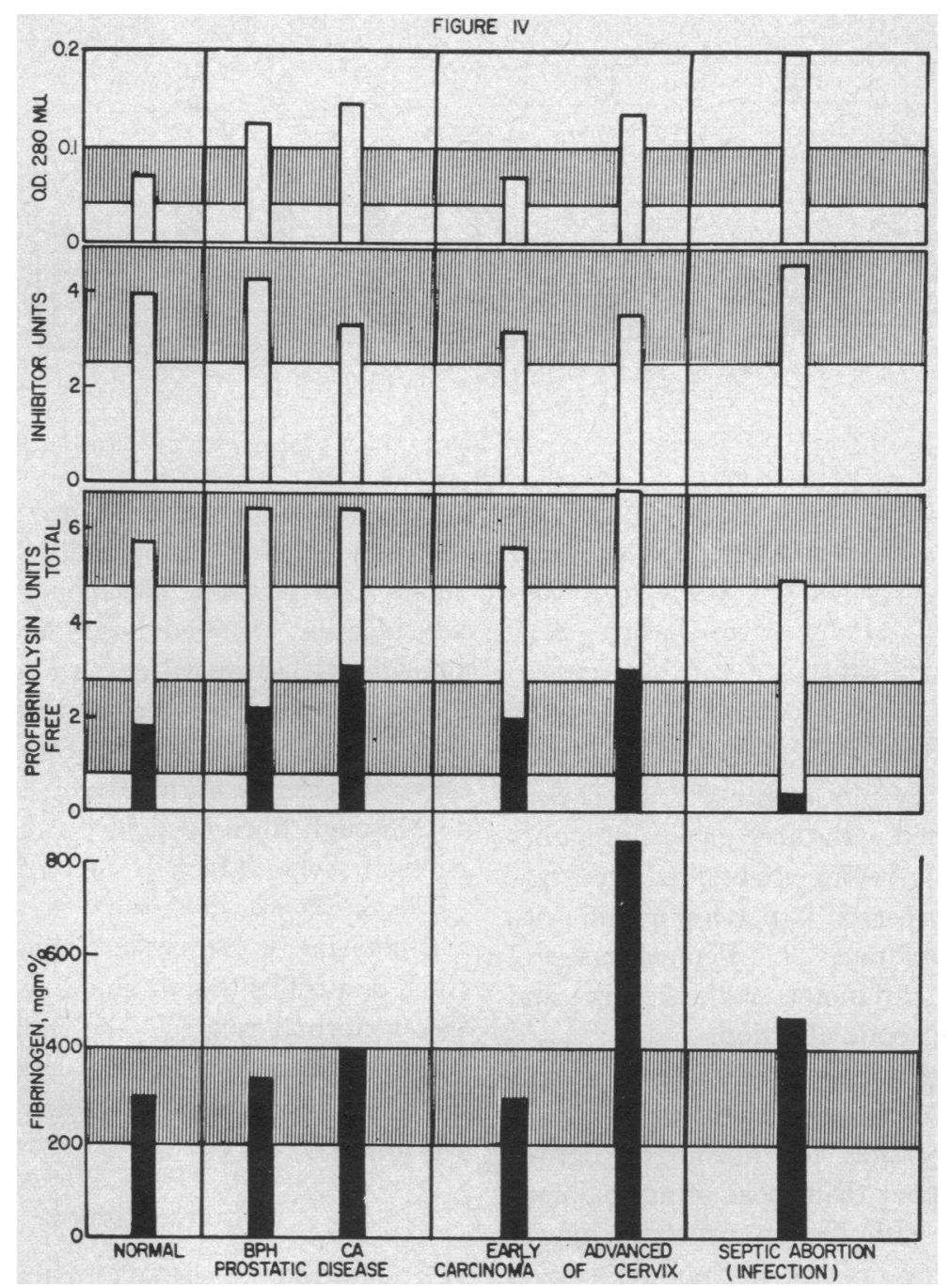

Fig. 4. Fibrinolytic Enzyme Activity in a Varifty of Diseases 
of inhibitors is generally believed to be associated with the albumin fraction of plasma. Therefore, an iso-electric precipitation of the enzyme at low ionic strength should remove these inhibitory factors. However, while it is recognized that all the possible inhibitors may not be removed ( 11 . 12), nevertheless, they are substantially reduced by this procedure. Shulman (13) has shown evidence to suggest that fibrinogen itself appears to produce an inhibitory effect on fibrinolysin.

While fibrinolysin is usually thought of as acting only on fibrinogen and fibrin, it must be remembered that it is a general proteolytic enzyme. Although albumin and globulin do not appear to be destroyed by this enzyme, other constituents of the plasma may be. Recently, there have been reports of the destruction of clotting factors other than fibrinogen by this enzyme (14-16). Thus proaccelerin, platelets, antihemophilic globulin, and perhaps prothrombin, may all be hydrolyzed by fibrinolysin. Therefore, multiple clotting deficiencies may result from the activation of the fibrinolytic enzyme. The methods presented here, while measuring only a few of the numerous factors, do give a comprehensive picture of the processes involved.

The active fibrinolysin is an extremely labile enzyme which is apparently rapidly denatured both in vivo and in vitro. Although rapid clot lysis was observed in some samples of blood drawn in Cases $\mathrm{A}$ and $\mathrm{C}$ presented here, no significant active proteolysis was demonstrable. However, the fact that the total profibrinolysin was considerably reduced in both of these cases is strong suggestive evidence that the precursor has been activated and then denatured after it has removed the fibrinogen from the blood stream by hydrolysis. Conversely, fibrinogen levels remained normal in Cases $\mathrm{B}$ and $\mathrm{D}$, where profibrinolysin levels also stayed within a normal range, even under such conditions of stress as abruptio placentae and extensive surgical procedures.

It is suggested that in cases of afibrinogenemia. inhibitors of the activation process may first be reduced, perhaps by adsorption on the microsomes of tissue extract as suggested by Astrup (17). This removal of inhibitors may permit a portion of the profibrinolysin to be activated, either by enzymes of the tissue extract or by some other activator present in the blood stream as suggested by
Troll and Sherry (18). The proteolytic enzyme thus produced may then hydrolyze the fibrinogen and other clotting factors and perhaps cause the removal of more inhibitors. The whole process may then be repeated until a severe afibrinogenemia is encountered, which can be controlled only by the intravenous administration of fibrinogen. Since the active enzyme is rapidly destroyed, if sufficient fibrinogen is given to control the hemorrhage for a short period of time the procedure may then be reversed, as the patient's own protective mechanisms start to resynthesize the varicus factors involved, i.e., fibrinogen, inhibitors, and profibrinolysin.

The data presented on patients throughout pregnancy give an overall view of what may be expected to occur during normal pregnancy. Where many factors of the system vary from these normal levels, it may be supposed that there is an interdependence of these factors on each other. Johnson and Tillett (19) have shown that streptokinase injected into the blood stream of rabbits produced an active lytic enzyme accompanied by a moderate fall in serum inhibitors and fibrinogen and a striking fall in plasminogen (profibrinolysin). Lewis and Ferguson, using staphylokinase and fibrinolysin, obtained similar results in dogs (20).

The similarity in results in the two cases of severe hemorrhage from afibrinogenemia with those reported by the previously quoted authors, makes it seem probable that the same mechanisms were involved. The time required for afibrinogenemia to develop after Cesarean section in Case A (three hours) makes an enzymatic process of removal of fibrinogen more probable than a mechanism of intravascular defibrination by clotting. This case also negates the idea prevalent among obstetricians that afibrinogenemia will not develop once the uterus is emptied.

Case $\mathrm{C}$ emphasized the evidence previously presented from this laboratory (21) that even slightly decreased fibrinogen levels (125 to $175 \mathrm{mg}$. per cent) may be dangerous in the surgical patient and demonstrates that rapid plasma clot lysis may sometimes be a more effective test of a dangerous clotting defect than is the fibrinogen level.

The first enzyme levels found in both Cases $\mathrm{C}$ and $\mathrm{D}$, which are typical of cirrhotic cases, suggest that the hemorrhagic tendencies of these pa- 
tients may be at least partially due to fibrinolysin and sometimes to hypofibrinogenemia. The chronically low levels of profibrinolysin suggest that the enzyme is slowly but constantly going through a process of activation, utilization and destruction. The low inhibitors in these cases may be associated with the low serum albumin levels usually observed in cirrhotic patients. The results presented in Case $\mathrm{D}$ also point out the efficacy of giving serum albumin prophylactically, not only to restore the normal albumin-globulin ratio, but also to raise inhibitor levels.

The evidence presented here shows that advanced carcinoma is more apt to be accompanied by high levels of fibrinogen and profibrinolysin than low levels. This is in spite of the evidence presented by Tagnon (22) that a 10 to 12 per cent incidence of fibrinolysin and hypofibrinogenemia may be expected in cases of metastatic carcinoma of the prostate. However, these high levels may have been due to the fact that most of the patients had been on stilbesterol for some time before they were studied (23). Extremely high optical densities of TCA soluble products have been observed in most cases of advanced cancer. Severe infection is also apt to produce high levels of fibrinogen and optical density although the profibrinolysin is at low normal levels.

While the differences obtained between normal and cancer patients are not highly significant in most determinations except optical densities, the characteristic picture of high fibrinogen, high profibrinolysin, and high optical densities is found in cases of carcinoma and pregnancy while infection produces high fibrinogen and high optical densities. These are the same three categories in which so many of the "diagnostic tests" for cancer give similar positive results. Unfortunately, as with so many of the tests for cancer, these results vary only slightly from possible normal ranges and they are observed primarily only in cases of advanced carcinoma where the disease has usually already made itself evident in other ways.

\section{SUMMARY}

A group of methods for investigating the factors of the fibrinolytic enzyme system in human plasma is presented. These factors include fibrinogen, active fibrinolysin, "free" and total pro- fibrinolysin, and inhibitors. This set of determinations gives a more complete indication of changes taking place in the system than do the one or two assays usually employed for determination of fibrinolysis.

Normal obstetrical patients have been followed throughout pregnancy in order to establish base lines for comparison with cases of obstetrical complications. Normal nonpregnant levels are compared with cases involving surgical hemorrhage and disease states.

A study of these factors in cases of hemorrhage following abruptio placentae and surgery for cirrhosis of the liver indicates that fibrinolysis is probably the principle cause of afibrinogenemia. Whenever low fibrinogen levels are encountered, the total profibrinolysin and inhibitor levels are also reduced. It is suggested that the profibrinolysin is activated in these cases, thus reducing the quantity of precursor. The active fibrinolysin so formed destroys the fibrinogen by intravascular hydrolysis and is itself then rapidly denatured. The lability of the active enzyme makes it difficult to detect in vitro.

Many disease states such as cirrhosis of the liver, advanced carcinoma, benign prostatic hypertrophy and infection appear to present their own pattern of variation in the fibrinolytic enzyme system. These changes are probably secondary in nature.

\section{REFERENCES}

1. Ratnoff, O. D., and Menzie, C. A new method for the determination of fibrinogen in small samples of plasma. J. Lab. clin. Med. 1951, 37, 316.

2. Scott, E. V.Z., Matthews, W. F., Butterworth, C. E., Jr., and Frommeyer, W. B., Jr. Abnormal plasma proteolytic activity. Diagnosis and treatment. Surg. Gynec. Obstet. 1954, 99, 679.

3. Phillips, L. L., Montgomery, G., Jr., and Taylor, H. C., Jr. The role of the fibrinolytic enzyme system in obstetrical afibrinogenemia. Amer. J. Obstet. Gynec. 1957, 73, 43.

4. Phillips, L. L., Butler, B. C., and Taylor, H. C., Jr. A study of cytofibrinokinase and fibrinolysin in extracts of tissue from human myometrium, endometrium, decidua, and placenta. Amer. J. Obstet. Gynec. 1956, 71, 342.

5. Milstone, H. A factor in normal human blood whick. participates in streptococcal fibrinolysis. J. Immunol. 1941, 42, 109.

6. Coon, W. W., and Hodgson, P. E. Fibrinolysin in surgery patients. Surg. Gynec. Obstet. 1952, 95, 717. 
7. Fresh, J. W., Ferguson, J. H., and Lewis, J. H. Blood clotting studies in parturient women and the newborn. Obstet. Gynec. 1956, 7, 117.

8. Astrup, $\mathrm{T}$. Fibrinolysis in the organism. Blood 1956, 11, 781.

9. Tagnon, H. J., and Palade, G. E. Activation of proplasmin by a factor from mammalian tissue. J. clin. Invest. 1950, 29, 317.

10. Lewis, J. H., and Ferguson, J. H. Studies on a proteolytic enzyme system of the blood. II. Fibrinolysokinase activators for profibrinolysin. J. clin. Invest. 1950, 29, 1059.

11. Loomis, E. C., Ryder, A., and George, C., Jr. Fibrinolysin and antifibrinolysin: Biochemical concentration of antifibrinolysin. Arch. Biochem. 1949, 20, 444.

12. Ratnoff, O., Lepow, I. H., and Pillemer, L. The multiplicity of plasmin inhibitors in human serum, demonstrated by the effect of primary amino compounds. Bull. Johns Hopk. Hosp. 1954, 94, 169.

13. Shulman, N. R. Studies on the inhibition of proteolytic enzymes by serum. I. The mechanism of the inhibition of trypsin, plasmin and chymotrypsin by serum using fibrin tagged with $\mathrm{I}^{131}$ as a substrate. J. exp. Med. 1952, 95, 571.

14. Alagille, D., and Soulier, J. P. Action des enzymes protéolytiques sur le sang total "in vitro," modifications des facteurs de coagulation et du complément. Sem. Hôp. Paris 1956, 32, 355.

15. Soulier, J. P., Alagille, D., and Larrieu, M. J. Modifications "in vivo" des facteurs de coagulation dans les fibrinolyses; valeur du déficit en proaccélérine pour le diagnostic des protéolyses frustes ou latentes. Sem. Hôp. Paris 1956, 32, 359.

16. Lewis, J. H., Leary, D. C., Fresh, J. W., and Ferguson, J. H. Fibrinolytic fibrinogenopenia. Amer. J. Obstet. Gynec. 1958, 75, 418.

17. Astrup, T. The activation of a proteolytic enzyme in blood by animal tissue. Biochem. J. 1951, 50, 5.

19. Troll, W., and Sherry, S. The activation of human plasminogen by streptokinase. J. biol. Chem. $1955,213,881$.

19. Johnson, A. J., and Tillett, W. S. The lysis in rabbits of intravascular blood clots by the streptococcal fibrinolytic system (streptokinase). J. exp. Med. 1952, 95, 449.

20. Lewis, J. H., and Ferguson, J. H. Effects of intravenous injection in dogs of staphylokinase and dog serum fibrinolysin. Proc. Soc. exp. Biol. (N. Y.) 1949, 71, 677.

21. Phillips, L. L., Rowley, P. T., and Habif, D. V. Hypofibrinogenemia in surgical patients. Surg. Gynec. Obstet. 1956, 103, 443.

22. Tagnon, H. J., Whitmore, W. F., Jr., Schulman, P., and Kravitz, S. C. The significance of fibrinolysis occurring in patients with metastic cancer of the prostate. Cancer 1953, 6, 63.

23. Cottier, P., Leupold, R., and Scheitlin, W. Die hämorrhagische Diathese bei Prostatakarzinom und ihre Behandlung. Schweiz. med. Wschr. 1955, 85, 781. 